\title{
JURISPRUDENCIA ESPAÑOLA LESIÓN DEL DERECHO AL HONOR Y TRATAMIENTOS DE DATOS REFERIDOS AL INCUMPLIMIENTO DE LA OBLIGACIÓN DINERARIA
}

Alfredo Ferrante

Universitat de Girona

\section{1. $\mathrm{HeCHOS}^{1}$}

A, de profesión abogado, decide publicitar su despacho profesional mediante el servicio en línea de las Páginas Amarillas. Para ello, contrata el servicio por medio de la empresa $\mathrm{B}$ cuyo precio mensual es de 347,88 euros (alrededor de 269.254 pesos). El abogado negocia con la empresa B la "posibilidad de anulación a lo largo de la vigencia del contrato pagando la parte proporcional que lleve consumida y publicada en la red" concertando el contrato en día 22 de septiembre de 2010. Dicha cláusula, no presente en el contrato de adhesión, consta por anotación manuscrita. Después de algo más de un mes de la activación del servicio, el cliente ejerce su derecho de desistimiento mediante comunicación por correo electrónico a B. Habiendo ya pagado el primer mes, solicita en el correo electrónico que se cargue en su cuenta la cantidad correspondiente al tiempo que había hecho efectivo uso de los servicios publicitarios (correspondiente a 231,92 euros, alrededor de 179.502 pesos).

${ }^{1}$ STS (Sala de lo Civil, Sección $1^{\mathrm{a}}$ ) $\mathrm{N}^{\mathrm{o}}$ 267/2014, de 21 mayo (RJ2014/2948). Ponente: Excmo Sr. Rafael Saraza Jimena.
B hace caso omiso de esta comunicación y sigue girando los recibos mensuales. Frente a tal comportamiento, A dio orden a su banco para que devolviera los recibos girados y envió a B un segundo correo electrónico donde pide que se le comunique una cuenta donde ingresar el importe proporcional debido.

$\mathrm{B}$, no considerando resuelto el contrato y frente al impago del abogado, comunica los datos del cliente a C (empresa titular de los ficheros morosos) para que lo incluya en el fichero "ASNEF", solicitud efectuada sin haber previamente hecho ningún requerimiento de pago al abogado. La consecuencia de la inserción en la lista de morosos es la negativa en

${ }^{2}$ El fichero del ASNEF, es una base de datos sobre solvencia patrimonial y crédito de datos relativos al cumplimiento e incumplimiento de obligaciones financieras y crediticias gestionada por Equifax Iberica S.L. (en los hechos C), que se nutre de la información aportada por sus propios socios: la Asociación Nacional de Establecimientos Financieros de Crédito, la Asociación Española de Factoring y la Asociación Española de Leasing, esencialmente integrando la mayoría de los Bancos u otras entidades financieras o de telecomunicaciones como de los mayores operadores de servicios. Más información en www.equifax.es/ederechos/asnef_20024.html. 
la renovación de un aval bancario de vivienda, solicitada por un empleado del despacho jurídico. A, habiéndose enterado de su inclusión en el fichero de morosos solamente de facto, se dirige a $\mathrm{C}$ ejercitando el derecho de cancelación de sus datos personales incluidos en tal registro. En esta comunicación, el abogado no solo manifestaba no haber recibido la notificación de inclusión en el registro prevista por ley $^{3}$, sino que, además, adjunta

1) el contrato celebrado con $B$ en que aparecía la posibilidad de desistimiento unilateral del contrato,

2) la comunicación remitida a $B$ haciendo uso de esta facultad, así como

3) la comunicación en la que informaba que había devuelto el recibo mensual y le solicitaba lo girara por la cantidad proporcionalmente correcta.

El titular de los ficheros $\mathrm{C}$, sin embargo, no cancela los datos en cuanto afirma que B le "confirmó" la presencia de la deuda.

Después de haber estado citado y concurrir en la causa, en la vista de una demanda de conciliación formulada por $\mathbf{B}$ (en que esta última no compareció), el abogado pide judicialmente la condena solidaria tanto de $\mathrm{B}$ como de $\mathrm{C}$ a una indemnización -cuantificada en treinta mil eurospor daños morales causados por la intromisión ilegítima en el derecho al

${ }^{3}$ Esta debe comunicarse a tenor del art. 29.2 de la Ley Orgánica No 25/99, de 13 de diciembre, de Protección de Datos de Carácter Personal y 40 de su reglamento de desarrollo (real decreto $\mathrm{N}^{\mathrm{o}} 1720 / 2007$, de 21 de diciembre). honor, la intimidad y la propia imagen y daños y perjuicios causados por la vulneración de lo establecido en la Ley Orgánica de Protección de Dats.

El tribunal de primera instancia ${ }^{4}$, en sentencia confirmada por la Corte de Apelaciones ${ }^{5}$, estima parcialmente la demanda considerando responsable solo la empresa $B$, pero no al titular de los tratamientos de los datos personales $(\mathrm{C})$. Considera que la primera sí incurrió en una intromisión ilegítima en el derecho fundamental al honor del demandante, aunque no en los derechos fundamentales a la intimidad y a la propia imagen del mismo, condenándola a una cuantía de cinco mil euros por concepto de daño moral, mandando cancelar definitivamente el registro del demandante en el fichero de morosos, como fue requerido en medida cautelar por el abogado.

El abogado interpone recurso de casación, reclamando una mayor cuantificación de la indemnización y la condena solidaria de las dos entidades, ya que la gestora y titular del registro (C) incurre en responsabilidad al no velar por la exactitud de los datos que publicaba y no corrigió la irregularidad a pesar de conocer la inexactitud de los datos durante más de dos años. El Tribunal Supremo español acoge parcial-

${ }^{4}$ JPI Sevilla n. 12 , sentencia de 30 diciembre 2011 (JUR 2013/192820). Obsérvese que la sentencia también desestima la demanda reconvencional, por la que se reclamaba la cuantía de las 231, 92 euros, formulada por B por falta de conexión entre su pretensión y las objeto de las demanda principal.

${ }^{5}$ SAP Sevilla (sec. $8^{\mathrm{a}}$ ) $\mathrm{N}^{\mathrm{o}}$ 429/2012, de 20 septiembre (JUR 2013/147023). 
mente el recurso, admitiendo la responsabilidad solidaria, pero confirma el importe indemnizatorio establecido en primera instancia.

\section{2. ÁMBITO NORMATIVO}

El abogado reclama una indemnización de daños morales por la intromisión ilegítima al honor, la intimidad y la propia imagen, cuyo fundamento se encuentra en el art. 9.3 de la Ley de Protección Civil de Derechos al Honor, Intimidad Personal y Propia Imagen $^{6}$. Dichos perjuicios han sido

${ }^{6}$ Ley Orgánica $N^{\circ} 1 / 1982$, de 5 de mayo y posteriores modificaciones $(B O E, 14$ de mayo de 1982, n. 115).

Art. 9.2: "La tutela judicial comprenderá la adopción de todas las medidas necesarias para poner fin a la intromisión ilegítima de que se trate y, en particular, las necesarias para:

a) El restablecimiento del perjudicado en el pleno disfrute de sus derechos, con la declaración de la intromisión sufrida, el cese inmediato de la misma y la reposición del estado anterior. En caso de intromisión en el derecho al honor, el restablecimiento del derecho violado incluirá, sin perjuicio del derecho de réplica por el procedimiento legalmente previsto, la publicación total o parcial de la sentencia condenatoria a costa del condenado con al menos la misma difusión pública que tuvo la intromisión sufrida.

b) Prevenir intromisiones inminentes o ulteriores.

c) La indemnización de los daños y perjuicios causados.

d) La apropiación por el perjudicado del lucro obtenido con la intromisión ilegítima en sus derechos.

Estas medidas se entenderán sin perjuicio de la tutela cautelar necesaria para asegurar su efectividad".

Art. 9.3: "La existencia de perjuicio se presumirá siempre que se acredite la intromisión ilegítima. La indemnización se extenderá al daño moral, que se valorará atendiendo causados por la vulneración del tratamiento de datos personales, por lo que reclama también los daños materiales debido a la no renovación del aval bancario a tenor del art. 19.1 de la $\mathrm{LPD}^{7}$. Por lo tanto, destaca la presencia contemporánea de dos disposiciones ad hoc relativas a la indemnización, la primera de carácter más general, ya que se refiere a una amplia categoría de intromisión ilegítima de derechos fundamentales, y la segunda, dedicada al incorrecto tratamiento de los datos personales, disposición también más extensa que refiere a cualquier dato personal y al incumplimiento de las obligaciones dinerarias; específicamente, permite no solo el tratamiento de los datos accesibles al públicos sino la incorporación de los datos de los morosos facilitados por el acreedor o por quien actúe por su cuenta o interés (cfr. art. 29.2 de la LPD y art. 37.2 del $\left.\mathrm{RPD}^{8}\right)$.

Debe destacarse en el ordenamiento español la presencia de una

a las circunstancias del caso y a la gravedad de la lesión efectivamente producida, para lo que se tendrá en cuenta, en su caso, la difusión o audiencia del medio a través del que se haya producido."

${ }^{7}$ Ley Orgánica 15/1999, de 13 de diciembre, de Protección de Datos de Carácter Personal (en BOE, No 298 de 14 de diciembre de 1999, y posteriores modificaciones). Art. 19.1: "Los interesados que, como consecuencia del incumplimiento de lo dispuesto en la presente Ley por el responsable o el encargado del tratamiento, sufran daño o lesión en sus bienes o derechos tendrán derecho a ser indemnizados". Para una panorámica sobre la ley véase v.gr. Lesmes SeRRANo (coord.) (2008).

${ }^{8}$ Real decreto $\mathrm{N}^{\mathrm{o}} 1720 / 2007$, de $21 \mathrm{de}$ diciembre (BOE, 19 de enero de 2008, n. 17). Sobre el reglamento véase $v . g r$. MARÍ y VilasaU (coord.) (2008); Zabía de la Mata (coord.) (2007); Martínez Martínez (coord.) (2009). 
norma expresa, el art. 29 de la LPD que no solo legitima el tratamiento de datos públicos sino que, en su segundo párrafo $^{9}$, permite que se traten también datos de deudores comunicados directamente por el acreedor al titular de la base de datos.

En la sentencia, se confirma la postura asumida por el pleno en $2009^{10}$, por la cual la errónea inclusión en un registro de morosos viola el derecho de honor, tipificando la intromisión ${ }^{11}$ y cuyo perjuicio se presume iuris et iure $^{12}$, a tenor del art. 9 de la Ley de

${ }^{9}$ Art. 29.2 de la LPD: "Podrán tratarse también datos de carácter personal, relativos al cumplimiento o incumplimiento de obligaciones dinerarias facilitados por el acreedor o por quien actúe por su cuenta o interés. En estos casos se notificará a los interesados respecto de los que hayan registrado datos de carácter personal en ficheros, en el plazo de treinta días desde dicho registro, una referencia de los que hubiesen sido incluidos y se les informará de su derecho a recabar información de la totalidad de ellos, en los términos establecidos por la presente Ley".

${ }^{10}$ STS (Sala de lo Civil, Sección Pleno), N ${ }^{\circ}$ 284/2009, de 24 de abril (RJ 2009/3166), relativa al cargo de la tarjeta VISA que no era debido y a la introducción en los registros de morosos Badex y Asnef-Equifax. Por un comentario a la sentencia, véase Fernández Martínez (2010), p. 19 y ss; PARRA LuCÁn (2009), p. 467 y ss.

${ }_{11}$ At. 7.7 L.O. N $^{\mathrm{O}}$ 1/1982: "Tendrán la consideración de intromisiones ilegítimas en el ámbito de protección delimitado por el artículo 2 de esta Ley (...) La imputación de hechos o la manifestación de juicios de valor a través de acciones o expresiones que de cualquier modo lesionen la dignidad de otra persona, menoscabando su fama o atentando contra su propia estimación".

${ }^{12}$ Art. 9.3 L.O. N ${ }^{\circ}$ 1/1982, de 5 de mayo: "La existencia de perjuicio se presumirá siempre que se acredite la intromisión ilegítima. La indemnización se extenderá al daño moral, que se valorará atendiendo a las circunstancias del caso y a la gravedad de la lesión efectivamente producida, para lo que se tendrá
Protección Civil de Derechos al Honor, Intimidad Personal y Propia Imagen. En este sentido, debe huirse de la aplicación de las disposiciones de carácter general, como podrían ser el art. 1902 del Código Civil español ${ }^{13}$, en el ámbito de responsabilidad extracontractual o en la contractual, el art. 1101 del mismo texto, normativa que comportaría la demostración de la existencia de perjuicios y su correspondiente prueba ${ }^{14}$.

Por lo tanto, de manera correcta, al igual que la posición tomada por el tribunal de primera instancia, no se consideran violados el derecho a la intimidad personal o a la propia imagen ${ }^{15}$, como en cambio lo solicitó

en cuenta, en su caso, la difusión o audiencia del medio a través del que se haya producido".

${ }^{13}$ Sobre la anulación de una sentencia de condena ex arts. 1902 y 1104 del Código Civil español a un banco en relación con la inscripción en el Registro de Aceptaciones Impagadas de un tenedor de una letra impaga, sin haber atendido a las alegatos del actor por la falsedad de la firma véase STS de 24 diciembre 1988 (RJ 1988/9815). En relación con un caso de intromisión ilegítima al derecho al honor donde la falta de veracidad de la información se debe a un caso de homonimia: STS (Sala de lo Civil, Sección 1ª) No 212/2006, de 7 de marzo (RJ 2006/5695)

${ }^{14}$ Cuando, en cambio, se ha visto que en caso de derecho al honor existe una presunción iure et iure por la ley orgánica $\mathrm{N}^{\circ} 1 / 1982$. Otra cosa es que se podría acudir a estas disposiciones cuando la violación de la protección de datos lesione otros derechos diferentes del derecho al honor: cfr. EgusQuiza BaLMASEDa (2009), pp. 182 y 183. Sobre la ley véase ya v.gr. Estrada ALONso (1989); De Verda y Beamonte (coord.) (2007).

${ }^{15}$ Sobre la autonomía de estos tres derechos: STC (Sala Segunda) n. 14/2003 de 28 enero (RTC 2003/14), STC (Sala Segunda) No 81/ 2001 de 26 de marzo (RTC 2001/81). Estos tres derechos, como declara la STS (Sala de lo Civil, Sección 1a) $\mathrm{N}^{\mathrm{o}} 770 / 2008$, de 26 de julio (RJ 2008/5510) no pueden confundirse siendo 
también el demandante, sino solo el derecho al honor.

Esta intromisión ilegítima -por cuya existencia es intrascendente que el fichero haya sido o no consultado por terceras personas ${ }^{16}$, , aunque se manifiesta mediante la violación de la normativa sobre protección de datos personales (al violarse las normas sobre tratamientos de datos personales: art. 29 de la LPD) tiene un fundamento independiente y autónomo y más elevado en la propia ley de protección de derechos al honor, recibiendo la indemnización a tenor de la ley ad hoc y en concreto el art. 9 de la LO $\mathrm{N}^{\circ} 1 / 1982$. Esta es, en definitiva, la postura de la sentencia comentada que confirma ${ }^{17}$ la indemnización de

"tres derechos distintos y no uno sólo trifronte". Por ello diferente sería la intromisión de la protección del derecho a la intimidad en su faceta de revelación del secreto profesional ex art. 7.4 (y no $e x$ art. 7.7) LO No 1/1982 por el cual es tal "la revelación de datos privados de una persona o familia conocidos a través de la actividad profesional u oficial de quien los revela.". Sobre el hecho de que la intromisión no viola el derecho a la intimidad sino al honor, posterior al 2009, v.gr. STS (Sala de lo Civil, Sección 1a) No 226/2012, de 9 de abril (RJ 2012/4638) comentada por Rubio Torrano (2012), p. 91 y ss.

${ }^{16}$ En cambio, sobre la necesidad de la divulgación en Chile: SCS de 26 de septiembre de 2006 (rol 514-2005).

${ }^{17}$ Relativamente al quantum, el Tribunal Supremo español desestima la solicitud de una mayor cuantía dado que los daños materiales (debido a la no renovación del aval) no se habían solicitado en la demanda originaria, como en cambio el abogado con posterioridad demandó en fase de apelación y de recurso. Por otro lado, confirma los importes relativos al daño moral, ya que estos no pueden retocarse en casación, salvo por error notorio o que no se hayan tomado en debida consideración los parámetros establecidos en el art. 9.3 L.O No 1/1982 (para este aspecto véase STS (Sala de lo Civil, Sección $1^{\mathrm{a}}$ ) $\mathrm{N}^{\mathrm{o}}$ los cinco mil euros. En concepto del Tribunal Supremo español, para que nazca el derecho a indemnizar, es suficiente que la primera y segunda instancias hayan motivado sus decisiones sin hacer recurso a la LDP ni a su reglamento. Por ello, aunque existe el art. 19 de la $\mathrm{LPD}^{18}$ que predispone una indemnización de los daños por el tratamiento ilícito de datos personales, es correcto aquel razonamiento. Afirma el Tribunal Supremo:

“en aplicación del principio general del carácter indemnizable de los daños sufridos por la inclusión incorrecta de los datos personales en un registro de morosos, ha aplicado la norma que regula específicamente la indemnización de los daños morales sufridos por la intromisión en el honor, causada en este caso por dicha inclusión en el fichero automatizado de datos personales".

Por ello, el recurrente no puede afirmar -a efecto de una mayor indemnización- que debe también te-

794/2013, de 16 de diciembre (RJ 2013\7840), aspecto que para el caso de quo no se da. Sobre los parámetros a tomar en consideración esquemáticamente v.gr. MARTín CASALS (1990), p. 388 y ss; Atienza NaVARro (2007), p. 281 y ss.

${ }_{18}$ Sobre el art. 19 vid. v.gr. Busto Lago (2006), pp. 2177 y ss. El autor evidencia que la responsabilidad puede referirse a dos momentos distintos, el de la creación del fichero de los datos y del tratamiento responsable del fichero de datos personales. En relación con la anterior LO No $5 / 1992$, y su art. 10, considera que debe diferenciarse entre titular y responsable del fichero: GRIMALT Servera (1999), p. 102, contra Ortí Vallejo (1994), pp. 116-117. 
nerse en consideración la violación del art. 19 de la LPD. En este sentido, el lesionado se encuentra frente a dos normas que legitiman la indemnización

a) una de carácter general rela-

b) otra expresamente prevista en la ley de Protección de datos: art. 19 de la LPD.

Sin embargo, la STS No 267/2014 es destacable ya que, por un lado, matiza sobre la aplicación de la LPD y de su RPD y por otro, entra en el mérito interpretativo de la disposición del art. 29 LPD.

\section{INTERPRETACIÓN DE LA LPD Y DE SU REGLAMENTO}

294 tiva al derecho al honor: art. 9 LO 1/1982 y

que se acaban de mencionar y de los altos valores constitucionales (art. 18.4 Constitución española ${ }^{21}$ ), debe reconocerse respecto de todo tipo de personas, incluso comerciantes y profesionales, aun más cuando el desprestigio profesional debe interpretarse por el Tribunal Supremo ${ }^{22}$ como una forma de lesión del derecho al honor. Por ello, la normativa sobre el tratamiento de los datos personales

"resulta de aplicación a todos los ciudadanos, sean o no comerciantes o profesionales. Cuestión distinta es que algunos datos relativos a los comerciantes (el nombre comercial, el domicilio, el teléfono, las actividades empresariales, etc.) puedan ser objeto de tratamiento automatizado (...) al quedar fuera del ámbito de aplicación de la LPD (...) al no afectar al derecho fundamental"

constitucionalmente protegido.

Por ello, el Tribunal Supremo español deja clara la interpretación que debe efectuarse de determinadas normas de jerarquía inferior, cuales son la LPD y su reglamento. Llega a la con-

y lo sustenta fundamentándolo no solo sobre la normativa nacional sino en el art. 8 de la Carta de Derechos Fundamentales ${ }^{19}$ de la Unión Europea y del Convenio $\mathrm{N}^{\mathrm{o}} 108$ del Consejo de Europa (cfr. arts. 1 y 5$)^{20}$. La sentencia va más allá y afirma que este derecho fundamental, en virtud de las normas

${ }^{19}$ Ratificado por instrumento de 27 de enero de 1984 (BOE, 15 de noviembre de 1985, n. 274).

${ }^{20}$ DOCE, 18 de diciembre de 2000, n. 364
${ }^{21}$ Art. 18.4 Cesp: "La ley limitará el uso de la informática para garantizar el honor y la intimidad personal y familiar de los ciudadanos y el pleno ejercicio de sus derechos". Sobre el carácter constitucional de este derecho también se manifiestan v.gr. STS (Sala de lo Civil, Sección 1a) N $^{\mathrm{o}} 12 / 2014$, de 22 de enero (RJ 2014/998); STS No 226/2012, citada.

${ }^{22}$ El Tribunal aquí aporta como apoyo las STS (Sala de lo Civil, Sección 1a) $\mathrm{N}^{\mathrm{o}} 733$ / 2004, de 19 de julio (RJ2004/5460), STS N²26/ 2012, citada. 
clusión de que, aunque el art. $2.3 \mathrm{del}$ RPD afirma:

"los datos relativos a empresarios individuales, cuando hagan referencia a ellos en su calidad de comerciantes... se entenderán excluidos"

de su aplicación, debe entenderse que esta disposición no asume relevancia, ya que hay normativa de rango superior en sentido totalmente contrario:

"un reglamento no puede excluir de la protección de una ley orgánica de desarrollo de un derecho fundamental a quienes la Constitución, el Convenio, la Directiva y la propia ley orgánica no ha excluido";

aun más cuando no cabe una interpretación extensiva y como en el caso de quo, donde el abogado es una "profesión liberal" diferente del concepto de comerciante o empresario individual.

\section{REINTERPRETACIÓN \\ DE LA RESPONSABILIDAD POR INTROMISIÓN ILEGÍTIMA}

Ya he destacado que la normativa española, en su art. 29 de la LPD, permite tratar los datos personales relativos al cumplimiento o incumplimiento de obligaciones dinerarias facilitados por el mismo acreedor, sin el consentimiento del afectado (art. 29.2 de la LPD). Aquí, aunque la LPD exige que los datos deben ser exactos (art. 4.3 de la $\mathrm{LPD}^{23}$ ), ni ella ni su reglamento imponen al titular del fichero de morosos la comprobación de la existencia, certeza y vencimiento de la deuda, al contrario de lo que ocurre con el acreedor informante.

$\mathrm{El}$ art. 19 de la LPD afirma que los interesados tienen derecho a una indemnización como consecuencia del comportamiento del responsable o el encargado del tratamiento, pero no expresa quien debe ser el responsable $^{24}$. Sin embargo, el art. 43 del RPD afirma que es responsable "el acreedor o quien actúe por su cuenta" y que comunique los datos al titular del fichero ${ }^{25}$, no requiriendo, por lo tanto, una condena de este último.

${ }^{23}$ Atentamente la doctrina observa: "la característica abstracta de la veracidad en que la calidad de los datos se manifiesta se expresa en el reglamento bajo el término certeza", al exigir el art. 38 del RPD que la deuda es cierta. En estos términos véase Hualde Manso (2013), p. 53.

24 "Art. 19 LPD. Derecho a indemnización

1. Los interesados que, como consecuencia del incumplimiento de lo dispuesto en la presente Ley por el responsable o el encargado del tratamiento, sufran daño o lesión en sus bienes o derechos tendrán derecho a ser indemnizados.

2. Cuando se trata de ficheros de titularidad pública, la responsabilidad se exigirá de acuerdo con la legislación reguladora del régimen de responsabilidad de las Administraciones públicas.

3. En el caso de los ficheros de titularidad privada, la acción se ejercitará ante los órganos de la jurisdicción ordinaria”.

${ }^{25}$ Art. 43 del RPD: "1. El acreedor o quien actúe por su cuenta o interés deberá asegurarse que concurren todos los requisitos exigidos en los artículos 38 y 39 en el momento de notificar los datos adversos al responsable del fichero común.

2. El acreedor o quien actúe por su cuenta o interés será responsable de la inexistencia o inexactitud de los datos que hubiera facilitado para su inclusión en el fichero, en los términos previstos en la ley orgánica 15/1999, de 13 de diciembre". 
Por ello esta circunstancia ha servido con anterioridad para excluir la responsabilidad del titular del fichero de morosos $^{26}$. Sin embargo, la STS No 267/2014 va un paso más allá, toma expreso partido y afirma:

"como responsable del tratamiento de los datos obrantes en el registro de morosos del que es titular, le compete atender la solicitud de cancelación o rectificación del afectado cuando la misma sea suficientemente fundada porque los datos incluidos en el fichero no respetan las exigencias de calidad derivadas de las normas reguladoras del derecho. $\mathrm{Y}$ por las mismas razones ha de responder de los daños y perjuicios causados al afectado cuando se hayan incumplido estas obligaciones".

En este sentido, aboga y exige un comportamiento activo por su parte, aún más cuando la persona que pida la rectificación de los datos realiza su solicitud de manera documentada y razonable:

"el interesado ejercita el derecho de rectificación o cancelación ante el responsable del registro de morosos, si la reclamación se realiza de manera documentada y justificada, el responsable de este

${ }^{26}$ Por unos pronunciamientos de la jurisprudencia menor que condena a la entidad que ha comunicado los datos, reenvío a Busto LAGO (2006), p. 2211 y ss. fichero ha de satisfacer este derecho en los términos previstos en el art. $16 \mathrm{LPD}^{27}$ no puede limitarse a trasladar la solicitud al acreedor, para que este decida, y seguir acríticamente las indicaciones de este, dando una respuesta estandarizada al afectado al que niega la cancelación".

Por ello, el control del responsable debe entrar en el fondo del asunto todas las veces que existan razonables dudas sobre la inexistencia de la deuda.

Aquí, definitivamente el Tribunal Supremo eleva la responsabilidad solidaria de la empresa titular del registro de morosos incluso diciendo que es su actuación la más perjudicial para el sujeto e virtud de la fuerza expansiva que puede tener la incorporación de un dato incorrecto en el fichero:

"el tratamiento de datos personales que puede causar daños más graves al interesado no es el efectuado por el acreedor en su fichero comercial, sino el realizado por la empresa titular del registro de morosos, cuyo fichero común puede ser consultado por un número indeterminado de empresas asociadas, con el descrédito que ello puede suponer para el afectado, provocando la intromisión ilegítima en su derecho al honor y daños morales y patrimoniales".

${ }^{27}$ Por el cual "el responsable del tratamiento tendrá la obligación de hacer efectivo el derecho de rectificación o cancelación”. 
Por todo ello, para el Tribunal Supremo español, frente a una acreditación razonable y suficiente de que la inclusión en el registro es improcedente, debe exigirse un comportamiento activo del titular del fichero no pudiéndose

"adoptar una actitud pasiva, limitándose a pedir (...) la confirmación de la procedencia de la inclusión de los datos".

Así, en el caso sub lite, se

"debió examinar la solicitud y dar una respuesta con base en el carácter fundado o no de la misma, solicitando en su caso a B que justificara la confirmación de los datos, no limitándose a ser un mero transmisor de la solicitud al acreedor".

La reconstrucción argumentativa del tribunal se basa también en el hecho de que el mismo RPD impone al acreedor que ha comunicado los datos del deudor, mantener a disposición del responsable del fichero la documentación acreditativa de los requisitos (art. 38.3 del RDP). Esto, $a$ contrario, serviría para evidenciar que este último sujeto puede y debe entrar en el fondo a la hora de valorar una solicitud de cancelación.

Curioso es que, aunque la ley exige entre los requisitos el haber hecho previamente un requerimiento de pago al deudor y que de los hechos resulte probado que en el caso no se realizó, la sentencia no se pronuncie sobre el punto. Hubiera sido una bue- na ocasión para confirmar la postura que el Tribunal Supremo ya ha manifestado ${ }^{28}$, exigiendo este requisito para la inscripción, como lo exigía también la Agencia de Protección de Datos ${ }^{29}$ y lo hace el art. 38 del RPD ${ }^{30}$.

${ }^{28}$ Estos requisitos serían: a) Existencia previa de una deuda cierta, vencida, exigible; b) que no hayan transcurrido seis años desde la fecha en que hubo de procederse al pago de la deuda o del vencimiento de la obligación o del plazo concreto si aquella fuera de vencimiento periódico. c) Requerimiento previo de pago a quien corresponda el cumplimiento de la obligación: STS (Sala de lo contencioso administrativo, sección $6^{\text {a }}$ de 15 de julio de 2010 , recurso contencioso-administrativo $\mathrm{N}^{\mathrm{o}}$ 26/2008 (RJ 2011/954); STS (Sala de lo Civil, Sección $1^{\mathrm{a}}$ ) $\mathrm{N}^{\mathrm{o}} 13 / 2013$ de 29 de enero (RJ 2013/1835).

${ }^{29}$ La disposición primera de la Instrucción N $^{\circ}$ 1/1995 de la Agencia de Protección de Datos, relativa a la Prestación de Servicios de Información sobre Solvencia Patrimonial y Crédito $(B O E$, n. 54 , de 4 de marzo de 1995), exigía para la inclusión de los datos de carácter personal en los ficheros relativos al cumplimiento o incumplimiento de obligaciones dinerarias a) Existencia previa de una deuda cierta, vencida y exigible, que haya resultado impagada. b) Requerimiento previo de pago a quien corresponda, en su caso, el cumplimiento de la obligación. Esta instrucción se dictó en relación con el derogado art. 28 de la ley orgánica No 5/1992 que corresponde al actual art. 29 de la LPD).

${ }^{30}$ Requisito que, sin embargo, no estaba previsto en el antiguo reglamento relativo a la ley orgánica 5/1992 (Reglamento de Seguridad de Ficheros Automatizados de Datos de Carácter Personal: real decreto 994/1999, de 11 de junio, en BOE, 25 junio 1999, n. 151).

Obsérvese que la redacción original del art. 38 del RPD ha sido parcialmente declarada nula por la STS (Sala de lo ContenciosoAdministrativo, Sección $6^{\text {a }}$ ), de 15 julio de 2010 , recurso contencioso-administrativo $\mathrm{N}^{\circ}$ 25/2008 (RJ 2010/6271), eliminando el art. 38.2 por el cual "no podrán incluirse en los ficheros de esta naturaleza datos personales sobre los que exista un principio de prueba que de forma indiciaria contradiga alguno de 
Si anteriormente los jueces no consideraron que el art. 19 de la LPD fuera útil para justificar un mayor importe indemnizatorio, sí que lo aplican para dictaminar la obligación de resarcir al responsable o encargado del tratamiento de los datos sobre el art. 19 de la LPD, mediante una interpretación conjunta con el art. 23 de la directiva europea sobre Protección de Datos:

"Si el responsable o el encargado del tratamiento no respetara las exigencias derivadas de los principios que regulan la calidad de los datos tratados, y como consecuencia de dicha infracción se causaran daños y perjuicios de cualquier tipo a los afectados, el art. 19 LPD, en desarrollo del art. 23 de la Directiva ${ }^{31}$, les reconoce el derecho a ser indemnizados".

los requisitos anteriores". Sobre el punto véase esquemáticamente Hualde Manso (2013), p. 53 y ss; en relación con la nulidad véase PARRA LUCÁN (2011), p. 81 y ss.

${ }^{31}$ Directiva 95/46/CE del Parlamento Europeo y del Consejo, de 24 de octubre de 1995, relativa a la protección de las personas físicas en lo que respecta al tratamiento de datos personales y a la libre circulación de estos datos (DOL 23 de noviembre de 1995, n. 281). Art 23: "1. Los Estados miembros dispondrán que toda persona que sufra un perjuicio como consecuencia de un tratamiento ilícito o de una acción incompatible con las disposiciones nacionales adoptadas en aplicación de la presente Directiva, tenga derecho a obtener del responsable del tratamiento la reparación del perjuicio sufrido.

2. El responsable del tratamiento podrá ser eximido parcial o totalmente de dicha responsabilidad si demuestra que no se le puede imputar el hecho que ha provocado el daño".
En definitiva, la sentencia toma explícito partido contra la falta de control sobre la lista de morosos al realizar incorporaciones de manera casi automática y arbitraria por parte de los acreedores, legitimados por el art. 29.2 de la LPD, aspecto que ya se ha producido con otros registros de titularidad privada (y no pública) ${ }^{32}$. La STS No 267/2014 es enfática en el rechazo de estas prácticas abusivas, legitimadas por el art. 29.2 de la LPD, por el cual

"podrán tratarse también datos de carácter personal relativos al cumplimiento o incumplimiento de obligaciones dinerarias facilitados por el acreedor o por quien actúe por su cuenta o interés".

En este sentido, se exige un control efectivo sobre la inscripción de los datos de los morosos comunicados por los acreedores. No solo confirma la postura jurisprudencial por la cual debe exigirse una información verídica sino que acaba la obra empezada en 2013 por el Tribunal Supremo, el que, dada la gran trascendencia por

${ }^{32}$ Circunscrito a los bancos, se da en el caso del RAI donde la práctica de estas entidades ha sido definida como "un uso bancario que se presenta como mal uso por extralimitado, imprudente y precipitado (...) ya que el RAI no cuenta con amparo legal suficiente y sólo es práctica bancaria que exige una correcta utilización, por lo que ha de rechazarse cuando se presenta abusiva y arbitraria": STS (Sala de lo Civil, Sección 1a) $\mathrm{N}^{\mathrm{O}}$ 660/2004 de 5 de julio (RJ 2004/4941). Aquí se considera violado el derecho al honor en relación con un moroso inserto en el RAI por letras de cambio, cuya firma en la aceptación era falsa. 
sus efectos del registro de morosos, evidenció que

"la conducta de quien maneja estos datos debe ser de la máxima diligencia para evitar posibles errores" ${ }^{\prime 3}$.

Finalmente, identifica el contenido de esta diligencia que debe manifestarse mediante un comportamiento activo. Por ello, frente a una solicitud motivada y justificada:

"no puede limitarse a seguir las indicaciones del acreedor que facilitó los datos, ha de realizar su propia valoración del ejercicio del derecho de rectificación o cancelación realizado por el afectado, y darle una respuesta fundada.

Lo contrario implicaría una restricción injustificada del derecho a la protección de datos de los interesados cuyos datos sean incluidos en un registro de los previstos en el art. 29.2 LPD".

En este sentido, se supera de forma definitiva la postura de 2012, que consideraba que, al tenor del art. 43.2 del RDP 1720/2007 ${ }^{34}$

${ }^{33}$ STS (Sala de lo Civil, Sección $1^{\text {a) }}$ ) No 13/ 2013, citada; STS (Sala de lo Civil, Sección 1a), $\mathrm{N}^{\circ}$ 176/2013 de 6 de marzo (RJ 2013/2587); si en el primer caso se hizo previamente requerimiento de pago (que condujo a la ausencia de intromisión ilegítima), en el segundo no.

${ }^{34}$ Art. 43.2 RDP: "El acreedor o quien actúe por su cuenta el interés será responsable de la inexistencia o inexactitud de los datos que hubiera facilitado para su inclusión en el fichero en los términos previstos en la Ley Orgánica 15/1999, de 13 de diciembre”. "el mantenimiento de los datos, su exactitud y veracidad están bajo la exclusiva responsabilidad del acreedor que comunica el impago ${ }^{35}$ ";

por lo tanto, condenaba solo a la entidad que había suministrado los datos, aunque se había pedido la responsabilidad solidaria también del titular de los ficheros morosos. En este sentido, el Tribunal, en la sentencia en comento ( $\mathrm{N}^{\circ} 267 / 2014$ ), vuelca totalmente la impostación asumida en primera instancia y confirmada por la Corte de Apelaciones, por la cual

"la comprobación de la existencia, certeza y vencimiento de las deudas controvertidas no son incumbencia del titular del registro por exceder lógicamente de sus competencias".

Esta "lógica" viene desmontada por el Tribunal Supremo que -brillante y atento a los desarrollos recientes del Tribunal Superior de Justicia- fundamenta la responsabilidad bajo la consideración que el responsable del tratamiento de los datos "debe examinar debidamente" el fundamento

${ }^{35}$ STS No 226/2012, citada. El sujeto, debido a una suplantación de personalidad, había sido incluido en el fichero ASNEF y no pudo comprarse un coche. Recientemente, se confirma la condena del acreedor que comunica una deuda "contingente supeditada a la estimación del conflicto judicial y que finalmente resultó inexistente" en STS (civil, sec. $1^{\mathrm{a})}, \mathrm{N}^{\mathrm{o}} 12 / 2014$, citada; sin embargo, aquí no se había solicitado la responsabilidad solidaria en conjunto con el titular del fichero, por ello no se entra en la cuestión que aquí se está tratando. 
de la petición formulada por el interesado (cfr. art. 12 letra b); art. 14.1 letra a) directiva 95/46) ${ }^{36}$. De esta manera, se da un importante paso sobre la responsabilidad solidaria tanto de quien comunica el dato, como de quien lo administra, auspiciada ya en parte por la doctrina ${ }^{37}$ y que hace revivir la obligación del responsable del fichero ${ }^{38}$.

${ }^{36} \mathrm{El}$ razonamiento aportado aquí por la STS n. 267/2014 se funda sobre § 77 STJUE 13 de mayo de 2014 asunto C 131/12. La sentencia es nota para proclamar el llamado "derecho al olvido", es decir, el derecho a exigir a Google - gestor de un motor de búsqueda- eliminar de la lista de resultados, obtenidos a partir de su nombre, vínculos a páginas web, publicadas legalmente por terceros y que contienen datos e información verídicos relativos a su persona. El fundamento es que estos datos e información pueden perjudicar al solicitante, quien requiere que dicha información "olviden" tras un determinado lapso. Para un comentario a esta sentencia ORdóñEz Solís (2014), p. 27 y ss; Plaza Penadés (2014), p. 15 y ss; Brotons Molina (2014), p. 107 y ss. Importante es ver el estudio del "encargado de protección de los datos personales", figura recogida en el art. 18.2 de la directiva 95/46: SANTAMARÍA Ramos (2011).

${ }^{37}$ A favor de la responsabilidad solidaria entre el responsable y encargado del tratamiento de datos personales, poder decisional sobre el tratamiento: cfr. GARCía Rubio (2001), p. 487.

${ }^{38}$ En relación con el art. 28 de la LO No 5/1992 de Regulación del Tratamiento Automatizado de los Datos de Carácter Personal, el Tribunal Supremo español mediante las STS (Sala de lo Contencioso-Administrativo, Sección $6^{\mathrm{a}}$ ) de 13 de abril de 2002 (RJ $2002 \backslash 4251)$ Recurso de casación para la unificación de doctrina; STS (Sala de lo Contencioso-Administrativo, Sección 6 6 ) 29 de julio de 2002 (RJ 2002/8643) y STS (Sala de lo Contencioso-Administrativo Sección $\left.6{ }^{\mathrm{a}}\right) 3$ de diciembre de 2002 (RJ 2003/87), consideró que debe responder no quien suministró, sino el responsable el fichero.

\section{Contrato DE ADHESIÓN}

Y AUTONOMÍA CONTRACTUAL

Aunque la temática principal de la sentencia es la responsabilidad por tratamiento incorrecto de un dato personal de la cual puede derivar la lesión del derecho al honor, quiero hacer hincapié que, en sus líneas, la sentencia destaca otro importante aspecto: la posibilidad de negociar un contrato de adhesión. Aunque esto en la práctica no es utilizado, no se impide y el caso de quo nos da un brillante ejemplo. Clara, en este sentido, debe ser la primacía que tiene cualquier cláusula manuscrita frente a las predispuestas en un formulario o en un contrato estándar, aspecto que deja expresamente claro el Código Civil italiano en su art. 1342.

\section{HACIA UNA NECESARIA REFORMA DEL SISTEMA ACTUAL CHILENO}

Los razonamientos de sentencia del Tribunal Supremo español, son de indudable interés para el Derecho chileno en la óptica de la responsabilidad por daño moral que deriva de la incorrecta información en los registros DICOM, Boletín Comercial o de la Superintendencia de Bancos e Instituciones Financiera.

$\mathrm{Al}$ no existir en Chile una norma parecida a la española que regule de forma expresa la posibilidad de que el acreedor comunique el nombre del deudor a un registro de morosos de carácter privado (art. 29 del LPD), queda abierta la posible problemática de una responsabilidad no solo de quien ha comunicado sino tanto del responsa- 
ble del fichero como de quien lo está tratando. Hoy día la responsabilidad por daño moral por lesión al derecho al honor ya se ha consolidado en la práctica, aceptándose la inaplicación del art. 2331 del $C C$ chileno y consecuentemente, la apertura del referido resarcimiento en estas situaciones.

El respeto y la protección a la vida privada y a la honra, anclados al art. 19.4 de la Constitución Política de la República, han derrotado las limitaciones -ya criticadas por la doctrina $^{39}$ - impuestas por la literalidad $^{40}$ del art. 2331 del $C C$. No solo el Tribunal Constitucional, desde el año $2008^{41}$ ha dejado clara esta postura, recientemente consolidada ${ }^{42}$, sino que

${ }^{39}$ V.gr. AlessandRi Rodríguez, SOMARRIVA Undarraga, Vodanovic Haklicka (1998), p. 489; Corral Talciani (2004), p. 77

${ }^{40}$ Cfr. Barros Bourie (2006), p. 294.

${ }^{41}$ Como es sabido, este recorrido empieza con la STC de 10 de junio de 2008 (rol 943), al cual han seguido copiosos requerimientos de inaplicabilidad o de incostitucionalidad, total o parcial. Entre muchas: STC de 15 de abril 2014 (rol 2513), STC de 29 de enero 2014 (rol 2255), STC 29 de marzo de 2011 (rol 1798); STC de 24 de mayo de 2011 (rol 1723-10); STC 15 de marzo de 2011 (rol 1741); STC 15 de marzo de 2011 (rol 1679); STC de 9 de noviembre de 2010 (rol 1419); STC de 23 de septiembre de 2010 (rol 1463), STC de 16 de abril de 2009 (Rol 1185). Sobre el punto véase Larrain Páez (2011), p. 151 y ss; Linazasoro CAMPos (2010); NúÑEZ Poblete (2012), p. 199 y ss. Sobre el daño moral en general para el Derecho chileno v.gr. Domínguez Hidalgo (2003).

${ }^{42}$ Importantes son los razonamientos, en relación con el art. 2331 del $C C$, de SCS de 24 de octubre de 2013 (rol 2422): "la norma resulta desproporcionada, al impedir, de modo absoluto y a priori, la indemnización del daño moral cuando se estima lesionado el crédito u honra de una persona por imputaciones injuriosas. Se afecta, así, en su esencia un derecho amparado por la Constitución (artículo 19, $\mathrm{N}^{\mathrm{o}} 4^{\circ}$ )" la Ley sobre el Tratamiento de Datos personales de $2012^{43}$ la protege aún más, especificando la protección que ya la ley $\mathrm{N}^{0} 19.628$ inauguró ${ }^{44}$. En este sentido, es indudable que la raigambre de la indemnización por lesión al derecho al honor en estos casos, proviene de la evolución y la elevación al derecho fundamental de la protección de datos personales por parte del Tribunal Constitucional ${ }^{45}$. Sin embargo, quedan algunos aspectos claves por resolver. Al igual que en la óptica española ${ }^{46}$, el derecho a la protección a la vida privada y al honor tienen una protección constitucional nacional e internacional. Este derecho tiene una sobredimensión que se refleja, por una parte, en el art. 8 de la Convención sobre Derechos Humanos, así como en el art. 11 de la Convención Americana sobre Derechos Humanos ${ }^{47}$.

${ }^{43}$ Ley No 20.575 de 14 de febrero de 2012.

${ }^{44}$ Véase ley $\mathrm{N}^{\circ} 19.628$, de 18 de agosto de 1999 y posteriores modificaciones. Para el historial de la ley consúltese el documento oficial en www.leychile.cl/Consulta/portada hl?tipo_norma=XX1\&nro_ley=19628. Véase Anguita Ramírez (2007). Sobre un informe sobre el proyecto de ley de protección del honor y la intimidad de la persona (Cámara de Diputados de la República de Chile, Boletín, No 2370/07); véase PeÑa GonZÁlez (2004), pp. 75-104. Véase también $v . g r$. Pfeffer URQUiaga (2000), p. 465 y ss.

${ }^{45}$ Sobre el punto me remito v.gr. a QUEzAda Rodríguez (2012).

${ }^{46}$ Art. 18.1 Constitución española: "Se garantiza el derecho al honor, a la intimidad personal y familiar y a la propia imagen". Art. 18.4 Constitución española "La ley limitará el uso de la informática para garantizar el honor y la intimidad personal y familiar de los ciudadanos y el pleno ejercicio de sus derechos".

${ }^{47}$ Esta última relación, ha sido destacada expresamente por la misma Corte Suprema: SCS de 24 de octubre de 2013 (rol 2422). 
El verdadero paso adelante, puede ser impulsado por la actual propuesta de reforma del art. 19.4 de la Constitución Política de la República, ingresada $^{48}$ en junio de 2014, por la cual se añadiría:

"Toda persona tiene derecho a la protección de sus datos personales y obtener su rectificación, complementación y cancelación, si estos fueren erróneos o afectaren sus derechos, como asimismo a manifestar su oposición, de acuerdo con las disposiciones establecidas en la ley.

Su tratamiento sólo podrá hacerse por ley o con el consentimiento expreso del titular".

302
No cabe duda que la constitucionalización de este sistema impulsaría una apropiada reforma ${ }^{49} \mathrm{y}$ una mayor tutela de los datos personales. Tam-

${ }^{48}$ Proyecto de reforma constitucional que "consagra el derecho a protección de los datos personales" y que actualmente está en el primer trámite del senado, en Boletín Senado No 9384-0 en www.senado.cl/appsenado/templates/ tramitacion/index.php?boletin_ini=9384-07

${ }^{49}$ Ya se ha destacado la carencia de un organismo público encargado de velar por el cumplimiento de la LPD v.gr. Matus AREnA (2013), p. 201. Obsérvese la presencia desde el año 2009, de un proyecto de reforma constitucional que crea una agencia de protección de datos personales, que, sin embargo, ha sido archivado en marzo de 2014: Véase Boletín $\mathrm{N}^{\mathrm{o}}$ 6594-07, en www.senado.cl/appsenado/ templates/tramitacion/index.php?boletin ini=9384-07. De carácter más amplio es el proyecto de reforma de la ley $\mathrm{N}^{\circ} 19.628$ de la Comisión de Economía de la Cámara de Diputados: Boletín No 8143-03, en www. senado.cl/appsenado/templates/tramitacion/ index.php?boletin_ini=9384-07. bién fomentaría no solo la promulgación de una normativa administrativa $^{50}$ y penal ${ }^{51}$ ad hoc, que complemente y refuerce la actual acción habeas data sino que su desarrollo permitiría, además, regular los aspectos civiles, en especial la indemnización del derecho al honor generado por la vulneración de la protección de los datos personales, como sucedería por el uso erróneo o equivocado las bases crediticias y morosas.

Por ello, son maduros los tiempos para una adecuada reforma de la actual normativa en aras de una mayor tutela en relación con la violación de derechos fundamentales como el honor (o prestigio) y a un tratamiento verídico de los datos. Independientemente de la futura y auspiciadora aprobación de una reforma constitucional, es pertinente regular de un modo detallado la posible introducción de datos personales por los acreedores en los ficheros de morosos de naturaleza privada, para evitar las problemáticas que en España se han producido, en especial, en cuanto a la responsabilidad, solidaria o no, del acreedor y del responsable de la base de datos.

${ }^{50}$ Por ejemplo, a pesar de la aprobación del Reglamento del Registro de Banco de Datos Personales a cargo de organismos públicos, que manda su inscripción en el Registro Civil (decreto $\mathrm{N}^{\circ} 770$ de 11 de noviembre de 2000), en la actualidad, no existe un órgano ad hoc que controle el registro de los ficheros públicos privados y el Servicio de Registro Civil no tiene, en la práctica, ningún poder sancionatorio para que se cumplan las disposiciones legales por parte de los responsables de los bancos de datos personales.

${ }^{51}$ Actualmente destaca solo la regulación de los delitos contra el respeto y protección a la vida privada y pública de la persona y la familia, por modificación de la ley $\mathrm{N}^{\circ} 19.423$. 
Al fin y al cabo, el envío de los datos de naturaleza patrimonial para su publicación en el Boletín de Informaciones Comerciales, se prevé expresamente por la ley. Así, notarios, juzgados, bancos y otras asociaciones o instituciones deben comunicar la información sobre cheques, pagarés y letras y pueden $^{52}$ también, comunicar cuotas morosas de créditos. No obstante, independiente de la voluntariedad de la comunicación, es importante destacar que una vez efectuadas nace la obligación de rectificación cuando las obligaciones o cuotas morosas resulten "indudablemente pagadas o se hubieran extinguido de otro modo legal" (art. 4 decreto 59/1928). Aquí es fundamental destacar que la normativa prevé la obligación, por parte de los acreedores, de informar sobre esta nueva situación al responsable del registro o del banco de datos. Por ello, debe destacarse que existe una preciso deber - una vez efectuado el pago o extinguida la obligación- de rectificar dentro de siete días hábiles, para enmendar datos incorrectos (cfr. art. 19 ley $\mathrm{N}^{\circ} 19.628$; art. 4 decreto 59/1928). Estas disposiciones pueden generar una responsabilidad bien precisa del acreedor ${ }^{53}$, pero también del

${ }^{52}$ Véase art. 1 decreto 59 de 28 de marzo de 1928, en particular el art. 1.4 que afirma: “(...) los bancos, sociedades financieras y administradoras de mutuos hipotecarios y cooperativas de ahorros y créditos podrán remitir la nómina de los deudores morosos en el servicio de sus préstamos o créditos".

${ }^{53}$ Sin profundizar estos temas en este contexto, véase sentencias que indemnizan por inclusión errónea en DICOM, por parte del banco demandado, v.gr.: SCS de 20 de julio de 2009, sala $3^{\text {a }}$ (rol 6775-2007); SCS 14 de diciembre de 2009, sala $3^{\text {a }}$ (rol 2073-2008); responsable de los datos como, por ejemplo, DICOM. Efectivamente, una vez recibidos por el $\mathrm{BIC}$, este procesa y distribuye la información entre los burós de crédito ${ }^{54}$ que celebran un contrato de prestación de servicios con privados, otorgándoles, mediante los propios boletines, información sobre morosidades y similares, información que los burós tiene la obligación de controlar, ya que la tratan con ánimo lucrativo.

En este contexto, la sentencia en comento avanza y marca la responsabilidad solidaria de ambos involucrados, situación aceptable también en Chile, según la normativa analizada, y el ánimo de ampliar la tutela del derecho al honor e intromisión ilegítima en los datos personales; el fundamento, radica en la constante capacidad de control y rectificación que deben tener ambos sujetos, aun más cuando se trate de un fichero de titularidad privada.

Por esta razón, si el responsable del fichero debe indemnizar a tenor de los arts. 16 y 23 de la ley $\mathrm{N}^{\circ} 19.628$ y del art. 3 de la ley 20.575/2012, el acreedor podrá ser condenado a tenor del art. 19 de la ley $\mathrm{N}^{\circ} 19.628$ o del art.

SCS 30 de noviembre de 2006, sala $3^{\text {a }}$ (rol 7-2005).

${ }^{54}$ Como informa atentamente el ex gerente general de la Cámara de Comercio de Santiago, en la práctica, las empresas del sector envían al Boletín de Información Comercial las cuotas morosas de sus carteras, lo que permite al ente centralizador procesar y distribuir esta información entre los burós de crédito (DICOM, Databusiness, Sinacofi y Siifa), los que, a su vez, la ponen a disposición de los interesado: Ortíz Tello (2009), p. 26. Se reenvía al autor que aporta también claras figuras esclarecedoras (op. cit., p. 27 y ss). 
4 del decreto $\mathrm{N}^{\mathrm{o}} 59 / 1928$, teniendo en cuenta el desarrollo jurisprudencial del art. 2331 del $C C$ y el preponderante crecimiento del reconocimiento constitucional de un derecho a la protección de datos personales, que ya es maduro y necesario.

El actual sistema permitiría, incluso, una evolución que podría conducir a la responsabilidad del acreedor "privado", como sucedería en el caso del contrato de arrendamiento. En la actualidad, el acreedor privado puede dictaminar sin enterarse, su condena indemnizatoria mediante una cláusula contractual que estipule que el arrendatario será insertado en una base de naturaleza privada, como el fichero DICOM, en caso de impagos. Esta es la práctica que se está desarrollando en virtud de la creación, por parte de DICOM, del fichero de morosos de contratos de arrendamientos, donde es la misma titular de la base de datos la que aconseja, en virtud de la autonomía contractual de las partes, la introducción de dicha cláusula ${ }^{55}$, no existiendo una norma análoga al art. 29 de la LPD española. Lo que se publicita como eventual remedio a favor del arrendador, se podría trasformar

${ }^{55}$ La cláusula que DICOM propone insertar en el contrato de arrendamiento es: "yo el arrendatario, individualizando en la comparecencia autorizo al Arrendador y/o Corredor de Propiedades para que, separada e individualmente, en caso de simple retardo, mora o incumplimiento total o parcial de las obligaciones contraídas en el presente contrato de arrendamiento, mis datos personales y las demás derivadas de éste puedan ser tratados y/o comunicados a terceros en la base de datos del Boletín Electrónico Dicom de Equifax", en www.dicom.cl/efx/hcl.01/pag/p.efx.hcl.divarriendo_landing.html en una condena a indemnizar en caso de que se hayan incorporado impropiamente los datos del arrendatario en el fichero de morosos.

Por todo ello, al margen de que tal vez se considera que la tutela de la ley $\mathrm{N}^{\mathrm{O}}$ 19.628 no se aplica a las personas jurídicas $^{56}$, el derecho a la protección de los datos personales en su ámbito más amplio debe prosperar ${ }^{57}$, incluso por otros futuros medios, ya que es oportuno recordar que "el honor, atributo de las personas naturales, se da en las personas jurídicas bajo la noción de prestigio o reputación ${ }^{58}$ ". Es necesario una apropiada reforma que tenga en consideración estas problemática, así como cualquier uso indiscriminado de

${ }^{56}$ Véase art. 2 letra ñ) por la cual, el titular de los datos es la "persona natural a la que se refieren los datos de carácter personal". V.gr. desestima la demanda de rectificación de un dato relativo al impago de facturas telefónica en el registro DICOM de una empresa por ser persona jurídica, al no aplicarse al caso de quo la limitación del art. 16 de la ley: Corte de Apelaciones de Santiago de 11 de noviembre de 2009 (rol 5114-2009). Considera que los datos personales del art. 2 letras f) y g) no son aplicables a las personas jurídicas: SCS (sala tercera) de 24 de septiembre de 2010 (Causa No $^{\circ} 4832 / 2010$. Resolución No 35856 )

${ }^{57}$ Sobre el análisis de las varias posturas a favor y en contra de la indemnización del derecho al honor para las personas jurídicas, me remito v.gr. LARRAIN PÁEz (2011), p. 158 y ss. y a la bibliografía $i v i$ citada.

${ }^{58}$ Domínguez Benavente (1991, p. 150). Se remite a este autor que comenta una interesante sentencia que ya en aquellos años indemniza, tanto por daños patrimoniales, como morales, a una empresa por desprestigio comercial (a la que se le negó un contrato ventajoso), debido a la inserción en el Boletín Comercial de la Información de que se protestó una letra de cambio que fue pagada oportunamente: Corte de Apelaciones de Concepción de 2 de noviembre de 1989 (rol 697-1989). 
la información; información que -obtenida mediante medios lícitos, pero mal utilizada- provoca una lesión de un derecho personal, no habiendo pasado un control de veracidad o no habiendo sido debidamente actualizada.

\section{BibLIOGRAFÍA CITADA}

Alessandri Rodríguez, Arturo, Manuel Somarriva Undarraga, Antonio VodanOvic HaKLICKa (1998). Tratado de Derecho Civil. Partes preliminar y general, I, Santiago: Editorial Jurídica de Chile.

Anguita Ramírez, Pedro (2007). La protección de datos personales y el derecho a la vida privada: régimen jurídico, jurisprudencia y derecho comparado: análisis de la ley No. 19.628 sobre protección de la vida privada ( protección de datos de carácter personal) modificada por la ley $N^{0}$ 19.812. Santiago: Editorial Jurídica de Chile.

Atienza Navarro, María Luisa (2007). "Algunas cuestiones acerca de la responsabilidad civil por los daños al honor, a la intimidad y a la propia imagen", en José Ramón DE VERDA y BEAmonte, (coord.). Veinticinco años de aplicación de la Ley Orgánica 1/1982, de 5 de mayo, de Protección Civil del Derecho al Honor, a la Intimidad Personal y Familiar y a la Propia Imagen. Cizur Menor (Navarra): Aranzadi.

Barros Bourie, Enrique (2006). Tratado de responsabilidad extracontractual. Santiago: Editorial Jurídica de Chile.

Brotons Molina, Olga (2014). "Caso Google: tratamiento de datos y derecho al olvido. Análisis de las conclusiones del abogado general C-131/12". Revista Aranzadi de derecho y nuevas tecnologías, $\mathrm{N}^{\mathrm{O}} 33$, Navarra.

Busto Lago, José Manuel (2006). "La responsabilidad civil de los responsables de ficheros de datos personales y de los encargados de su tratamiento". Aranzadi Civil, No 5 , Navarra.

Corral Talciani, Hernán (2004), Lecciones de responsabilidad civil extracontractual. Santiago: Editorial Jurídica de Chile.

De Verda y Beamonte, José Ramón (coord.) (2007). Veinticinco años de aplicación de la Ley Orgánica 1/1982, de 5 de mayo, de Protección Civil del Derecho al Honor, a la Intimidad Personal y Familiar y a la Propia Imagen. Cizur Menor (Navarra): Aranzadi.

Domínguez Benavente, Ramón (1991). "Indemnización de perjuicios, daño moral, persona jurídica, relación de causalidad. Leyes reguladoras de la prueba. Documentos emanados de terceros. Comentario a Sentencia de la Corte de Apelaciones de Concepción de 2 de noviembre de 1989". Revista de Derecho de la Universidad de Concepción, No 190, Concepción.

Domínguez Hidalgo, Carmen Aida (2003). El daño moral. $2^{\mathrm{a}}$ ed. Santiago: Editorial Jurídica de Chile.

Egusquiza Balmaseda. María Ángeles (2009). Protección de datos: intimidady salud. Cizur Menor (Navarra): Thomson Reuters Aranzadi.

Estrada Alonso, Eduardo (1989). El derecho al honor en la Ley Orgánica, de 5 de mayo. Madrid: Civitas.

Fernández Martínez, Juan Manuel (2010), "Registros de Morosos. Revista Aranzadi Doctrinal, $\mathrm{N}^{\circ}$ 1. Navarra. 
García Rubio, M ${ }^{\mathrm{a}}$ Paz (2001), "Bases de datos y confidencialidad en Internet", en Joseba Aitor EchEBARRÍA SAENZ (coord.). El comercio electrónico. Madrid: Edisofer.

Grimalt Servera, Pedro (1999). La responsabilidad civil en el tratamiento automatizado de datos personales. Granada: Comares.

Hualde Manso, Teresa (2013). "Ficheros de morosos, nulidad del Reglamento de Protección de Datos y derecho al honor". Revista Doctrinal Aranzadi Civil-Mercantil, No 8 . Navarra.

Larrain Páez, Cristián Andrés (2011). "Algunas cuestiones relevantes sobre el derecho al honor y la responsabilidad civil, en partícular sobre el daño moral, el art. 2331 del Código Civil y la legitimación activa". Revista Chilena de Derecho Privado, No 17. Santiago. Diciembre.

Lesmes Serrano, Carlos (coord.) (2008). La Ley de protección de datos: análisis y comentario de su jurisprudencia. Valladolid: Lex Nova.

Linazasoro Campos, Gonzalo (2010). "Artículo 2331 del Código Civil: Las razones de su inaplicabilidad por inconstitucionalidad", en AA.VV. Estudios de Derecho Civil V. Santiago: AbeledoPerrot.

MARÍ Joana y Mónica Vilasau (coord.) (2008). El reglamento de protección de datos de carácter personal. Aspectos clave. Barcelona: Editorial UOC.

Martín Casals, Miquel (1990). "Indemnización por daños y otras medidas judiciales por intromisión en el derecho al honor", en Pablo SALVAdor Coderch (dir.). El mercado de las ideas. Madrid: Centro de Estudios Constitucionales.

Martínez Martínez, Ricard (coord.) (2009). Protección de datos: comentarios al reglamento de desarrollo de la LOPD. Valencia: Tirant lo Blanch.

Matus Arena, Jessica (2013). "Derecho de acceso a la información pública y protección de datos personales". Revisa Chilena de Dereecho y Tecnología. $\mathrm{N}^{\mathrm{O}}$ 1. Ciudad.

Núñez Poblete, Manuel (2012). "Desaplicación e inaplicación jurisdiccional de las leyes en chile: ejercicio de la jurisdicción y control concreto de constitucionalidad". Revista de Derecho Universidad Católica del Norte. Año 1. $\mathrm{N}^{\circ}$ 2. Ciudad.

Ordóñez Solís, David (2014). "El derecho al olvido en internet y la sentencia Google Spain”. Unión Europea Aranzadi. $\mathrm{N}^{\circ}$ 6. Navarra.

Ortí Vallejo, Antonio (1994), Derecho a la intimidad e informática (Tutela de la persona por el uso de ficheros y tratamientos informáticos de datos personales. Particular atención a los ficheros de titularidad privada). Granada: Comares.

Ortíz Tello, Claudio (2009), "La protección de datos personales y la información comercial", en Raúl Arrieta Cortés / Carlos Reusser Monsálvez coords.). Chile y la protección de datos personales. ¿están en crisis nuestros derechos fundamentales? Santiago: Universidad Diego Portales, Serie Políticas Públicas.

Parra Lucán, Ma Ángeles (2011). "Registros de morosos: Derecho civil y nulidad (parcial) del reglamento de desarrollo de la Ley Orgánica de protección de datos". Revista Doctrinal Aranzadi Civil-Mercantil, No 3 . Navarra.

Parra Lucán, Ma Ángeles (2009). "Vulneración del derecho al honor por 
incorrecta inclusión en un fichero de morosos (comentario de la sentencia del Tribunal Supremo de 24 de abril de 2009)", en Mariano YzQUIERdo TOlsada (ccord.). Comentarios a las Sentencias de Unificación de Doctrina (Civily Mercantil). Madrid: Dykinson, vol. III.

Peña González, Carlos (2004). "Informe sobre el proyecto de Ley de Protección del honor y la intimidad de las personas". Cuadernos de Análisis Jurídico, Colección Derecho Privado. Santiago: Universidad Diego Portales. Vol. I.

Plaza Penadés, Javier (2014). "Doctrina del Tribunal Supremo sobre el 'conocimiento efectivo' en la responsabilidad de los prestadores intermediarios y en el derecho al olvido". Revista Aranzadi de derecho y nuevas tecnologías, $\mathrm{N}^{\circ} 34$. Ciudad.

Pfeffer Urquiaga, Emilio (2000). "Los derechos a la intimidad o privacidad, a la honra y a la propia imagen. Su protección frente a la libertad de opinión e información". Ius et Praxis, $\mathrm{N}^{\circ}$ 1, Talca.

Quezada Rodríguez, Flavio (2012). "La protección de datos personales en la jurisprudencia del tribunal constitucional". Revisa Chilena de Dereecho y Tecnología, $\mathrm{N}^{\circ} 1$. Ciudad.

Rubio Torrano, Enrique (2012). "Inclusión indebida en fichero de morosos: intromisión ilegítima en el derecho al honor". Revista Doctrinal Aranzadi Civil-Mercantil. $\mathrm{N}^{\circ}$ 7. Navarra.

Santamaría Ramos, Francisco José (2011). El encargado independiente. Figura clave para un nuevo derecho de protección de datos. Madrid: La Ley.

Zabía de la Mata, Juan (coord.) (2007). Protección de datos: comentarios al Reglamento. Valladolid: Lex Nova.
Sentencias citadas

A. Sentencias del Tribunal

Constitucional español

STC (Sala Segunda) No 81/2001 de 26 marzo (RTC 2001/81).

STC (Sala Segunda) No 14/2003 de 28 enero (RTC 2003/14)

B. Sentencias del Tribunal Supremo español

STS (Sala de lo Civil) de 24 diciembre de 1988 (RJ 1988/9815).

STS (Sala de lo Civil, Sección $1^{\mathrm{a}}$ ) $\mathrm{N}^{\mathrm{o}}$ 733/2004, de 19 de julio (RJ 2004/ 5460).

STS (Sala de lo Civil, Sección 1 a) No $660 /$ 2004 de 5 julio (RJ 2004/4941).

STS (Sala de lo Civil, Sección 1 ${ }^{a}$ ) No 212/ 2006, de 7 marzo (RJ 2006/5695)

STS (Sala de lo Civil, Sección 1 $1^{\mathrm{a}}$ ) No $770 /$ 2008, de 26 de julio (RJ 2008/5510)

STS (Sala de lo Civil, Sección Pleno), No 284/2009, de 24 abril (RJ 2009/ 3166)

STS (Sala de lo Civil, Sección 1 ${ }^{\text {a) }}$ N $^{\circ}$ 226/ 2012, de 9 de abril (RJ 2012/4638)

STS (Sala de lo Civil, Sección 1 ${ }^{a}$ ) No $13 /$ 2013 de 29 enero (RJ 2013/1835).

STS (Sala de lo Civil, Sección 1a), No 176/ 2013 de 6 marzo (RJ 2013/2587).

STS (Sala de lo Civil, Sección $1^{\mathrm{a}}$ ) $\mathrm{N}^{\mathrm{o}}$ 794/2013, de 16 de diciembre RJ 2013\7840)

STS (Sala de lo Civil, Sección 1 ${ }^{\mathrm{a}}$ ) No 12 / 2014, de 22 de enero (RJ 2014/998).

STS (Sala de lo Civil, Sección $1^{\text {a }}$ ) No 267/ 2014, de 21 mayo (RJ 2014/2948).

STS (Sala de lo Contencioso-Administrativo, Sección $6^{\text {a }}$ ) de 13 de abril de 2002 (RJ 2002\4251) Recurso 
de casación para la unificación de doctrina.

STS (Sala de lo Contencioso-Administrativo, Sección 6 a) 29 de julio de 2002 (RJ 2002/8643).

STS (Sala de lo Contencioso-Administrativo Sección 6 3 ) 3 diciembre de 2002 (RJ 2003/87).

STS (Sala de lo contencioso administrativo, sección $6^{\mathrm{a}}$ ) de 15 de julio de 2010 recurso contencioso-administrativo No 26/2008 (RJ 2011/954).

STS (Sala de lo Contencioso-Administrativo, Sección $6^{\mathrm{a}}$ ), de 15 de julio de 2010, recurso contencioso-administrativo No 25/2008 (RJ 2010/6271).

C. Sentencias de la jurisprudencia menor español

SAP Sevilla (sec. $8^{\text {a }}$ ) n. 429/2012, de 20 308 de septiembre (JUR 2013/147023). JPI Sevilla No 12 , sentencia, de 30 de diciembre de 2011 (JUR 2013/192820).

D. Sentencias Tribunal de Justicia de la Unión Europea

STJUE 13 de mayo de 2014 asunto C $131 / 12$.

E. Sentencias del Tribunal Supremo

Chileno

STC de 10 de junio de 2008 (rol 943).

STC de 16 de abril de 2009 (rol 1185)

STC de 9 de noviembre de 2010 (rol 1419).
STC de 23 de septiembre de 2010 (rol 1463).

STC 15 marzo de 2011 (rol 1741).

STC 15 marzo de 2011 (rol 1679).

STC 29 de marzo de 2011 (rol 1798).

STC de 24 de mayo de 2011 (rol 172310).

STC de 29 de enero de 2014 ( $\operatorname{Rol} 2255)$.

STC de 15 de abril de 2014 (rol 2513).

F. Sentencias de la Corte Suprema Chilena

SCS de 26 de septiembre de 2006 (rol 514-2005).

SCS de 20 de julio de 2009, sala $3^{\text {a }}$ (rol 6775-2007).

SCS 14 de diciembre de 2009, sala $3^{\text {a }}$ (rol 2073-2008).

SCS 30 de noviembre de 2006, sala $3^{\text {a }}$ (rol 7-2005).

SCS (sala tercera) de 24 de septiembre de 2010 (Causa No 4832/2010. Resolución $\mathrm{N}^{\mathrm{o}} 35856$ )

SCS de 24 de octubre de 2013 (rol 2422)

G. Sentencias de las Corte

de Apelaciones

Corte de Apelaciones de Concepción de 2 de noviembre de 1989 (rol 697-1989).

Corte de Apelaciones de Santiago de 11 de noviembre de 2009 (rol 5114-2009). 